\title{
The occupations at increased risk of COPD: analysis of lifetime job-histories in the population-based UK Biobank Cohort
}

\author{
Sara De Matteis ${ }^{1,2}$, Deborah Jarvis ${ }^{1,2}$, Andrew Darnton ${ }^{3}$, Sally Hutchings ${ }^{4}$, \\ Steven Sadhra ${ }^{5}$, David Fishwick ${ }^{3}$, Lesley Rushton ${ }^{2,6}$ and Paul Cullinan ${ }^{1,2}$
}

Affiliations: ${ }^{1}$ National Heart and Lung Institute, Imperial College London, London, UK. ${ }^{2}$ MRC-PHE Centre for Environment and Health, London, UK. ${ }^{3}$ Centre for Workplace Health, Science Division, Health and Safety Executive, Buxton, UK. ${ }^{4}$ Division of Population Health, Health Services Research and Primary Care, School of Health Sciences, University of Manchester, Manchester, UK. ${ }^{5}$ Occupational and Environmental Medicine, College of Medical and Dental Sciences, University of Birmingham, Birmingham, UK. ${ }^{6}$ Dept of Epidemiology and Biostatistics, School of Public Health, Imperial College London, London, UK.

Correspondence: Sara De Matteis, Imperial College London, National Heart and Lung Institute, Emmanuel Kaye Building, 1b Manresa Road, London SW3 6LR, UK. E-mail: s.de-matteisवimperial.ac.uk

@ERSpublications

This study identified jobs at increased COPD risk using job-histories from a large population-based cohort. Results were confirmed in never-smokers and never-asthmatics. Focused preventive strategies are warranted to reduce the occupational COPD burden. http://bit.ly/2LcQPNt

Cite this article as: De Matteis S, Jarvis D, Darnton A, et al. The occupations at increased risk of COPD: analysis of lifetime job-histories in the population-based UK Biobank Cohort. Eur Respir J 2019; 54: 1900186 [https://doi.org/10.1183/13993003.00186-2019].

ABSTRACT Occupational exposures are important, preventable causes of chronic obstructive pulmonary disease (COPD). Identification of COPD high-risk jobs is key to focus preventive strategies, but a definitive job-list is unavailable.

We addressed this issue by evaluating the association of lifetime job-histories and lung function data in the population-based UK Biobank cohort, whose unprecedented sample size allowed analyses restricted to never-smokers to rule out the most important confounder, tobacco smoking. COPD was spirometrically defined as forced expiratory volume in $1 \mathrm{~s}$ /forced vital capacity ratio below the lower limit of normal. Lifetime job-histories were collected via OSCAR (Occupations Self-Coding Automatic Recording), a new validated online tool that automatically codes jobs into the UK Standard Occupational Classification v.2000. Prevalence ratios for COPD by employment duration in each job compared to lifetime office workers were estimated using robust Poisson regression adjusted for age, sex, centre and smoking. Only associations confirmed among never-smokers and never-asthmatics were considered reliable.

From the 116375 participants with complete job-histories, 94551 had acceptable/repeatable spirometry data and smoking information and were included in the analysis. Six occupations showed an increased COPD risk among never-smokers and never-asthmatics; most of these also with positive exposureresponse trends. Interesting new findings included sculptors, gardeners and warehouse workers.

COPD patients, especially never-smokers, should be asked about their job-history for better disease management. Focussed preventive strategies in COPD high-risk jobs are warranted.

This article has supplementary material available from erj.ersjournals.com

Received: Jan 252019 | Accepted after revision: April 212019

The content of this work is copyright of the authors or their employers. Design and branding is copyright @ERS 2019 


\section{Introduction}

Chronic obstructive pulmonary disease (COPD) is the third leading cause of death globally [1]. It is estimated that $\sim 15 \%$ of COPD cases are attributable to preventable occupational exposures overall [2], and up to $30 \%$ among never-smokers [3]. These percentages may increase in the near future due to the ageing workforce and the decrease in smoking habits in the general population. Defining a list of high-risk jobs for COPD is pivotal to focus preventive strategies and avoid the associated disability and mortality burdens. Several challenges have prevented this to date: workforce-based studies cannot explore the broad variety of jobs occurring in a general population; small studies have been underpowered to detect significant associations; there has been variable accuracy in the methods used to collect and code individual job-titles; and when studies have been large and used lifetime job-histories there has often been inadequate adjustment for the main confounder, tobacco smoking [2, 4-8]. We previously overcame the above limitations in a cross-sectional analysis of the UK Biobank study, a large UK population-based cohort with good-quality spirometry data and detailed lifetime information on tobacco smoking [9]. However, only current job at recruitment was available at the time; this is not only a potential limitation when assessing the risk for a chronic condition such as COPD, but also increases the chance of a healthy worker survivor effect (HWSE) bias [10]. To advance our analyses, we developed an innovative web-based tool, OSCAR (Occupations Self-Coding Automatic Recording), to reliably collect and automatically code lifetime job-histories for all Biobank participants [11]. The aim of the present work was to analyse the lifetime job-histories collected and coded by OSCAR to study the association between COPD and type and duration of each job held over a lifetime of employment. The unprecedented large sample size allowed us to restrict the analyses to never-smokers, in order to rule out confounding by smoking.

\section{Methods}

\section{Study base: the UK Biobank cohort}

The UK Biobank study is a large population-based prospective cohort of over half a million males and females recruited between 2006 and 2010 throughout the UK. Full details of the study protocol have been published elsewhere [9]. Briefly, a random sample of adults aged 40-69 years was identified from lists of those registered with the National Health Service in Britain, and who lived within specified distances of 22 health assessment centres. The reported response rate to the baseline UK Biobank survey was 5.5\% (503 325 out of 9.2 million invited). Baseline assessment included collection of extensive personal and demographic data (including age, sex, lifetime smoking history, current employment and doctor-diagnosed asthma) through computer-assisted self-administered questionnaire and face-to-face interview, and physical health measurements (including height, weight and spirometry).

\section{COPD definition}

Details of the spirometry protocol in the UK Biobank have been reported previously [9]. Among the 502649 UK Biobank participants who completed the baseline questionnaire, 457282 (91\%) subjects had lung function testing at recruitment. All spirometric measures were performed using a Vitalograph Pneumotrac 6800 (Maids Moreton, UK) in accordance with the American Thoracic Society (ATS)/European Respiratory Society (ERS) guidelines [12], but participants were allowed up to three attempts to provide two reproducible manoeuvres. The spirometer software compared the reproducibility of the first two blows and, if satisfactory (defined as a $\leqslant 5 \%$ difference in both forced vital capacity (FVC) and forced expiratory volume in $1 \mathrm{~s}$ (FEV1)), a third blow was not required. No post-bronchodilator measures were performed. For our work, we included acceptable spirometry data based on a quality appraisal of the flow curves from a random representative sample of these manoeuvres, as described previously [10]. We further excluded spirometry from participants who had smoked tobacco or used inhalers $1 \mathrm{~h}$ prior to testing. We defined COPD as FEV1/FVC below the lower limit of normal (i.e. the $5 \%$ lower tail of the normal distribution of the average predicted $\mathrm{FEV} 1 / \mathrm{FVC}$ ratio in a reference healthy never-smoking population) based on the age range of our study population. We used the Hankinson equation to calculate the predicted values for FEV1/FVC for each participant based on their individual age, sex and height [13-15]. Of note, $\sim 95 \%$ of the study participants reported a "White" ethnic origin.

\section{Lifetime job-histories collection and coding: the online OSCAR tool}

To collect and code the lifetime job-histories for all the UK Biobank participants using traditional methods (e.g. personal interviews or self-administered job questionnaires) was not feasible given the huge sample size; consequently, we developed and validated a web-based system (OSCAR); the methodological details have been published previously [11]. Briefly, OSCAR is an online categorical decision tree, based on a simplified, but faithful, version of the hierarchical structure of the UK Standard Occupational Classification (SOC), v.2000 [16], that uses a three-level decision tree displayed as job-lists on three linked web-pages starting with 15 major job groups (as a proxy for industry sectors), followed by job sub-groups and ending in specific job-titles (i.e. the original 353 four-digit SOC codes) to enable participants to 
quickly and easily find each job they have held in their life. On selection of a final job-title, a hidden four-digit SOC code is automatically assigned to that job and retained in the database. By design, OSCAR records full-time paid jobs held in life for $\geqslant 6$ months. The year of start and end for each job are recorded and displayed together with any job gap in a timetable that can be edited anytime by the participants and helps to visualise and accurately build a "career timeline".

\section{Statistical analysis}

To evaluate the association between lifetime occupational exposures and COPD risk, the job-histories were truncated, for each participant, to the time of spirometry used to define COPD; the same applies to exposures to the potential confounders.

We used a Poisson regression model with a robust error variance [17] to estimate prevalence ratios (PRs) and $95 \%$ confidence intervals for ever-employment and years of lifetime employment duration in each four-digit SOC-coded job using lifetime office workers (i.e. subjects who had only ever held office-based jobs) as a fixed reference category.

The final statistical model included, as adjustment covariates, age (5-year categories), sex, recruitment centre (22 categories) and lifetime tobacco smoking (ever/never, pack-years and years since quitting).

Many SOC-coded occupations were tested $(n=353)$, but we thought that the application of a formal statistical correction method (e.g. Bonferroni) might be too penalising, given that our approach was not completely agnostic (i.e. some occupations suspected $a$ priori to be associated with an increased COPD risk). Therefore, to reduce the chance of false positive associations, we used the following approach. Firstly, we tested the COPD risk for ever employment in each of the 353 jobs. Secondly, the associations showing formal statistical significance $(\mathrm{p}<0.05)$, and moderate strength of association $(P R \geqslant 1.30)$, and with at least five exposed persons in both cases and non-COPD participants, were tested for exposure-response trends by using lifetime job durations as categorical variables $(<0.5$ years; $0.5-10$ years and $>10$ years, to ensure enough subjects per duration category). Finally, the associations showing significant/borderline exposure-response trends were assessed in analyses restricted to 1) lifetime nonsmokers (to rule out residual confounding by tobacco smoking) and 2) those who did not report a doctor's diagnosis of asthma (to decrease the chance of disease misclassification given that only pre-bronchodilator spirometry measures were available). Only the associations confirmed in both sensitivity analyses were considered to be reliable and are reported for discussion.

All analyses were performed using Stata version 14 (StataCorp, College Station, TX, USA).

\section{Results}

OSCAR was administered by email to all UK Biobank participants with an available email address $(n=324$ 653) between June 2015 and February 2016; reminder emails were sent to partial- and non-responders up until December 2015. Only the complete and validated job-histories collected by OSCAR were included in this study. Overall, 116375 Biobank participants completed OSCAR (response rate 35.8\%). Of these, 94 551 had acceptable and repeatable spirometry data (according to the above reported criteria) and lifetime smoking information, and were consequently included in the final analyses. The detailed study flow diagram is reported in figure 1 .

FIGURE 1 Study flow-diagram in the UK Biobank cohort: analysis of the lifetime job-histories. SOC: UK Standard Occupational Classification; OSCAR: Occupations Self-Coding Automatic Recording; $\mathrm{FEV}_{1}$ : forced expiratory volume in $1 \mathrm{~s}$; FVC: forced vital capacity. \#: absolute contraindications to spirometry included chest infection in the past month li.e. influenza, bronchitis, severe cold, pneumonia); history of detached retina; heart attack or surgery to eyes, chest or abdomen in past 3 months; history of a collapsed lung; pregnancy (first or third trimester); and currently on medication for tuberculosis.
116375 among 324653 Biobank participants with an available email address provided complete SOC-coded lifetime job-histories using OSCAR

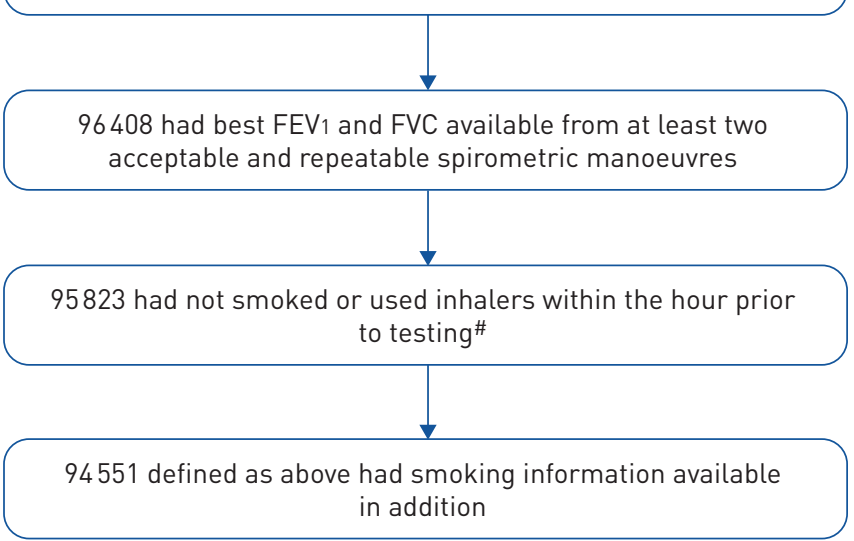


The main characteristics of our sample are shown in table 1. $\sim 54 \%$ were female; the mean \pm SD age was 55.9 \pm 7.6 years, similar in both sexes. The majority were lifetime nonsmokers $(\mathrm{n}=55596 ; 58.8 \%)$, both in males $(\mathrm{n}=21975 ; 52.6 \%)$ and females $(\mathrm{n}=33621 ; 63.7 \%)$; only a minority were current smokers $(\mathrm{n}=5302 ; 5.6 \%)$, both among males $(n=2750 ; 6.6 \%)$ and females $(n=2552 ; 4.8 \%) . \sim 11 \%$ of participants reported that a diagnosis of asthma had been made at some point during their life.

The overall prevalence of spirometry-defined COPD in our sample was 8.0\%, corresponding to 7606 cases, similar in both sexes. As expected, the prevalence of COPD was higher among current smokers $(16.8 \%)$ compared to ex- $(8.6 \%)$ and never-smokers $(6.9 \%)$.

\section{Lifetime job-histories: descriptive statistics}

The job-histories reported by the 94551 OSCAR participants covered the period from 1949 to 2016. The maximum number of jobs reported by each participant was 40 , with a median of three jobs (interquartile range 2-4). Among them 18642 (19.7\%) reported no job interruptions.

Within the 15 major job-group categories used by OSCAR as a proxy for industry sectors (figure 2), participants most commonly reported SOC-coded jobs in the office-based work sector $(n=48570 ; 51.4 \%)$ and the least in the mining sector $(n=1445 ; 1.5 \%)$. Sex differences were present: for example, males dominated the mining sector, and females the cleaning sector (supplementary table S1). Those who reported only ever working in office-based jobs numbered 19286 (20.4\% of our sample; 12282 females and 7004 males), and were used as a reference category in all the analyses.

\section{Analysis of ever-employment and lifetime job duration within each four-digit SOC-coded occupation}

Among the 353 evaluated SOC-coded occupations, 24 showed a statistically/borderline significant increased risk of COPD (supplementary table S2). We focused the analyses by lifetime employment duration on the 19 jobs with a significant $(\mathrm{p}<0.05)$ moderate COPD increased risk $(\mathrm{PR} \geqslant 1.30)$, and with at least five exposed persons in both COPD cases and "healthy" (i.e. non-COPD) participants. Table 2 includes, in order of four-digit SOC code, the 10 occupations that showed at least a moderate significant increased risk of COPD in one of the job duration categories, and significant/borderline positive exposure-response trends overall. When the analyses were restricted to never-asthmatics, the results remained substantially unchanged. However, the exclusion of ever-smokers from the analyses reduced the

TABLE 1 Selected characteristics of the study participants who collected their lifetime job-histories using OSCAR (Occupations Self-Coding Automatic Recording), overall and by sex, in the UK Biobank study, 2006-2010

\begin{tabular}{|c|c|c|c|}
\hline & Females & Males & Total \\
\hline Subjects & $52756(55.7)$ & $41795(44.2)$ & $94551(100)$ \\
\hline \multicolumn{4}{|l|}{ Age category years } \\
\hline $40-44$ & $5384(10.2)$ & 3892 (9.3) & $9276(9.8)$ \\
\hline $45-49$ & $7748(14.7)$ & $4956(11.9)$ & $12704(13.4)$ \\
\hline $50-54$ & $9783(18.5)$ & $6370(15.2)$ & $16153(17.1)$ \\
\hline $55-59$ & $11572(21.9)$ & $8643(20.7)$ & $20215(21.4)$ \\
\hline $60-64$ & $12093(22.9)$ & $11072(26.5)$ & 23165 (24.5) \\
\hline $65-69$ & $6063(11.5)$ & $6714(16.1)$ & $12777(13.5)$ \\
\hline $70-74$ & $113(0.2)$ & $148(0.4)$ & $261(0.3)$ \\
\hline Age years & $55.4 \pm 7.5$ & $56.6 \pm 7.7$ & $55.9 \pm 7.6$ \\
\hline \multicolumn{4}{|l|}{ Smoking status } \\
\hline Never & 33621 (63.7) & $21975(52.6)$ & $55596(58.8)$ \\
\hline Former (quit >6 months ago) & $16583(31.4)$ & $17070(40.8)$ & $33653(35.6)$ \\
\hline Current & $2552(4.8)$ & $2750(6.6)$ & $5302(5.6)$ \\
\hline Smoking pack-years" & $14.0(7-24)$ & $17.6(9-30)$ & $15.7(8-27)$ \\
\hline Time since quitting smoking ${ }^{\text {ๆ }}$ years & $19.4 \pm 11.4$ & $20.6 \pm 11.9$ & $20 \pm 11.7$ \\
\hline Doctor's diagnosis of asthma, ever & $6182(11.7)$ & $4335(10.4)$ & $10517(11.1)$ \\
\hline COPD status: current ${ }^{+}$ & $4224(8.0)$ & $3382(8.1)$ & $7606(8.0)$ \\
\hline \multicolumn{4}{|c|}{$\begin{array}{l}\text { Data are presented as } n(\%) \text { or mean } \pm \text { SD or median (interquartile range). COPD: chronic obstructive } \\
\text { pulmonary disease. } \# \text { : smoking pack-years defined as ( } \mathrm{n} \text { cigarettes/day } \div 20 \text { cigarettes) } \times n \text { years, among } \\
\text { ever-smokers; }{ }^{\text {I: }} \text { : time since quitting smoking defined as years since last smoked cigarette to time of } \\
\text { interview, among former smokers; }{ }^{+}: \text {spirometry-defined as forced expiratory volume in } 1 \mathrm{~s} / \text { forced vital } \\
\text { capacity ratio below lower limit of normal. }\end{array}$} \\
\hline
\end{tabular}




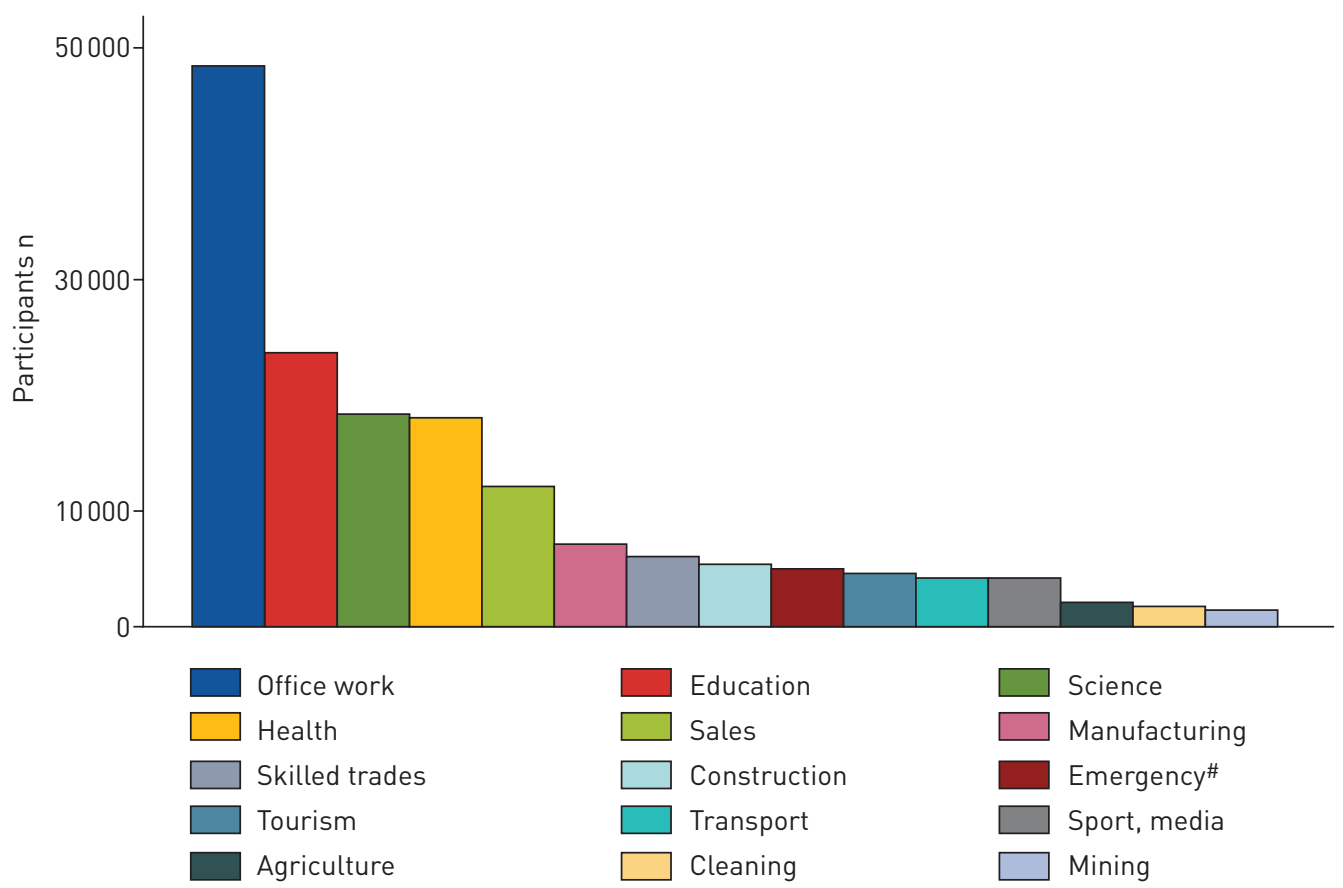

FIGURE 2 Distribution of UK Standard Occupational Classification (SOC)-coded jobs collected by OSCAR (Occupations Self-Coding Automatic Recording) among the UK Biobank participants by industry sector (major job-grouping in OSCAR). " : jobs in emergency services and armed forces.

associations with COPD risk to seven occupations only (indicated in table 2). Prevalence ratios in each of the 353 SOC-coded occupations by lifetime duration of employment are available for reference in supplementary tables S3, S4 and S5, for all subjects, never-asthmatics and never-smokers, respectively. Of note, among never-smokers only, a doubled COPD risk in "8121-paper and wood machine operatives" emerged with a positive exposure-response trend (supplementary table S5).

\section{Further sensitivity analysis: the "super-normal lung" effect bias}

Given the unexpected increased risk of COPD (confirmed in never-asthmatics) for "sport-related occupations", we examined whether this reflected "super-normal lung", a condition sometimes referred to as "dysanaptic alveolar growth", which is common in professional athletes. We excluded participants with both FEV1 and FVC $>100 \%$ predicted values, as previously suggested [18]. The exclusion of $97(\sim 42 \%)$ subjects with super-normal lung from the 233 working in this job category reduced the magnitude and significance of the previous risk estimates (table 3), while making similar exclusions for the other six jobs associated with increased COPD risk made little change.

\section{Discussion}

In a large UK population-based prospective cohort, we found that six SOC-coded occupations are associated with a significant increase in COPD risk: "sculptor, painter, engraver, art restorer"; "gardener, groundsman, park keeper"; "food, drink and tobacco processor"; "plastics processor, moulder"; "agriculture, and fishing occupations not elsewhere classified"; and "warehouse stock handler, stacker". These associations were confirmed among never-smokers and never-asthmatics and, for most, we found supporting positive exposure-response by categories of employment duration.

Compared to our previous cross-sectional analysis in the UK Biobank cohort [10], the largest previous population-based study on occupational exposures and COPD risk using a job-title approach, "manufacturing" emerged again as the sector at highest COPD risk. This industry has been previously reported at increased COPD risk because of the potential exposure to known respiratory occupational hazards [2]. In terms of job-titles, a few specific four-digit SOC-codes identified at increased COPD risk in the cross-sectional analysis were confirmed (e.g. "8111-food, drink and tobacco processors"), and new ones emerged within the same job categories (e.g. "8116-plastic process machine operator" to add to the previous "8114-chemical-related process operative"). This supports the validity of our previous findings in terms of job categories and adds new specific occupations to the list of high-risk COPD jobs so far identified that deserve further attention, probably due to the availability of lifetime job durations in this 
TABLE 2 Prevalence ratios (PRs) and 95\% confidence intervals of chronic obstructive pulmonary disease (COPD) risk spirometry-defined as forced expiratory volume in $1 \mathrm{~s} /$ forced vital capacity below lower limit of normal for lifetime job duration in an occupation coded as four-digit Standard Occupational Classification code 2000 in the UK Biobank study

\begin{tabular}{|c|c|c|c|c|c|c|c|c|}
\hline & \multicolumn{4}{|c|}{ All subjects } & \multicolumn{2}{|c|}{ Never-asthmatics } & \multicolumn{2}{|c|}{ Never-smokers } \\
\hline & Healthy exposed & d Cases exposed & PR $(95 \% \mathrm{CI})$ & $\mathrm{p}$-value for trend ${ }^{\#}$ & PR $(95 \% \mathrm{Cl})$ & $\mathrm{p}$-value for trend & PR $(95 \% \mathrm{Cl})$ & $\mathrm{p}$-value for trend ${ }^{\#}$ \\
\hline Subjects & \multicolumn{4}{|c|}{94551} & \multicolumn{2}{|c|}{84034} & \multicolumn{2}{|c|}{55596} \\
\hline \multicolumn{9}{|c|}{$\begin{array}{l}\text { 3411-sculptor, painter, } \\
\text { engraver, art restorer }\end{array}$} \\
\hline $0.5-10$ years & 86 & 11 & $1.12(0.55-2.28)$ & 0.05 & $1.14(0.50-2.62)$ & 0.08 & $0.96(0.32-2.90)$ & 0.004 \\
\hline$>10$ years & 88 & 12 & $1.77(1.01-3.11)$ & & $1.84(0.94-3.60)$ & & $2.99(1.59-5.61)$ & \\
\hline \multicolumn{9}{|c|}{$\begin{array}{l}\text { 3415-musician, bandsman, } \\
\text { instrumentalist }\end{array}$} \\
\hline $0.5-10$ years & 54 & 10 & $2.20(1.28-3.78)$ & 0.01 & $1.70(0.78-3.70)$ & 0.001 & $1.29(0.33-4.97)$ & 0.29 \\
\hline$>10$ years & 93 & 15 & $1.83(1.14-2.93$ & & 2.12 (1.28-3.53) & & $1.52(0.70-3.30)$ & \\
\hline \multicolumn{9}{|c|}{$\begin{array}{l}\text { 3433-public relations, } \\
\text { press officer }\end{array}$} \\
\hline $0.5-10$ years & 284 & 34 & $1.42(1.02-1.97)$ & 0.003 & $1.25(0.82-1.90)$ & 0.02 & $1.75(0.14-2.69)$ & 0.26 \\
\hline$>10$ years & 71 & 12 & $1.77(1.02-3.08)$ & & $2.00(1.08-3.69)$ & & $0.33(0.05-2.25)$ & \\
\hline \multicolumn{9}{|c|}{$\begin{array}{l}\text { 3442-sports coach, athlete, } \\
\text { instructor, scorer }\end{array}$} \\
\hline $0.5-10$ years & 122 & 19 & $1.78(1.15-2.76)$ & 0.004 & $1.69(0.98-2.91)$ & 0.04 & $2.13(1.25-3.63)$ & 0.03 \\
\hline$>10$ years & 80 & 12 & $1.69(0.92-3.09)$ & & $1.55(0.68-3.55)$ & & $1.32(0.57-3.06)$ & \\
\hline \multicolumn{9}{|c|}{$\begin{array}{l}\text { 5113-gardener, groundsman, } \\
\text { park keeper }\end{array}$} \\
\hline $0.5-10$ years & 329 & 37 & $1.24(0.89-1.73)$ & 0.007 & $1.19(0.79-1.79)$ & 0.07 & $1.08(0.64-1.84)$ & 0.03 \\
\hline$>10$ years & 138 & 19 & $1.72(1.13-2.63)$ & & 1.55 (0.91-2.64) & & $2.07(1.19-3.63)$ & \\
\hline \multicolumn{9}{|c|}{$\begin{array}{l}8111-\text { food, drink and tobacco } \\
\text { processor }^{n++}\end{array}$} \\
\hline $0.5-10$ years & 129 & 23 & $1.70(1.17-2.48)$ & 0.16 & $1.75(1.12-2.72)$ & 0.08 & $2.12(1.18-3.84)$ & 0.13 \\
\hline$>10$ years & 81 & 9 & $0.97(0.51-1.85)$ & & $1.18(0.59-2.35)$ & & $1.07(0.37-3.14)$ & \\
\hline \multicolumn{9}{|c|}{$\begin{array}{l}\text { 8116-plastics processor, } \\
\text { moulder }\end{array}$} \\
\hline $0.5-10$ years & 122 & 12 & $0.90(0.52-1.56)$ & 0.11 & $1.01(0.55-1.87)$ & 0.04 & $1.28(0.65-2.98)$ & 0.03 \\
\hline$>10$ years & 44 & 11 & & & $2.16(1.19-3.90)$ & & $2.74(1.15-6.48)$ & \\
\hline \multicolumn{9}{|c|}{$\begin{array}{l}\text { 9119-agriculture, and fishing } \\
\text { occupations n.e.c. }{ }^{\text {I. } f}\end{array}$} \\
\hline $0.5-10$ years & 140 & 27 & $1.76(1.22-2.55)$ & 0.009 & $1.49(0.91-2.43)$ & 0.09 & $2.29(1.36-3.86)$ & 0.01 \\
\hline$>10$ years & 19 & 2 & $1.12(0.29-4.28)$ & & $1.49(0.39-5.74)$ & & $1.07(0.16-7.00)$ & \\
\hline \multicolumn{9}{|c|}{$\begin{array}{l}\text { 9229-elementary personal services } \\
\text { occupations n.e.c. }\end{array}$} \\
\hline $0.5-10$ years & 74 & 9 & $1.17(0.61-2.24)$ & 0.015 & $1.27(0.59-2.71)$ & 0.02 & $0.92(0.24-3.53)$ & \\
\hline$>10$ years & 22 & 6 & $2.51(1.37-4.60)$ & & $2.90(1.38-6.09)$ & & & \\
\hline \multicolumn{9}{|c|}{$\begin{array}{l}\text { 9251-warehouse stock } \\
\text { handler, stacker }\end{array}$} \\
\hline $0.5-10$ years & 313 & 30 & $0.98(0.68-1.41)$ & 0.03 & $0.97(0.63-1.50)$ & 0.05 & $0.96(0.55-1.67)$ & 0.04 \\
\hline$>10$ years & 60 & 11 & $1.83(1.05-3.18)$ & & $1.84(1.00-3.42)$ & & $2.26(1.01-5.07)$ & \\
\hline
\end{tabular}

Data are presented as $\mathrm{n}$, unless otherwise stated. PRs $(95 \% \mathrm{Cl}$ ) were calculated using a Poisson model with robust variance adjusted for sex study centre (22 categories), age (5-year categories) and lifetime smoking exposure (ever, pack-years and years since quitting). Reference category: "always office workers"; healthy: non-COPD cases; cases: COPD cases; n.e.c: not elsewhere classified. ": from test for categorical trend. Only jobs that overall showed significant $(p<0.05)$ moderate COPD increased risk $(P R \geqslant 1.30)$ in one of the job durations are displayed; ף: occupations with significant associations with COPD risk confirmed among all subjects, never-asthmatics, and never-smokers; ${ }^{+}$: attendant, bakery assistant, blender, boiler, brewery worker, cook, crusher, cutter, dairy worker, dipper, dryer, filler, finisher, hand, machinist, maker, miller, mixer, preparer, pressman, vatman, washer; § : blender, cutter extruder, fabricator, filer, finisher, laminator, machinist, maker, moulder, operator, polisher, presser, trimmer, turner; ${ }^{f}$ : fishing boat (trawler) mate or bosun, fish farm assistant, fish breeder, aquarium assistant, fish hatcher, oyster bed worker, seaweed gatherer, shellfish digger, crabber, shrimper, fish breeder or shellfish cultivator, insect breeder, maggot breeder, mink farm assistant, sheep shearer, fruit and vegetable picker, hedger and ditcher, tree nursery worker/hand, horticultural worker, fruit picker, mushroom picker and other pickers; ${ }^{\# \#}$ : baths attendant, changing room attendant, stage hand, props hand, scenery hand.

analysis. In addition, in the present analysis we have found a significant increased COPD risk for "agriculture" occupations that did not emerge in the previous cross-sectional analyses. Agriculture is consistently reported as an important a priori high-risk COPD sector, probably because of potential exposure to organic and inorganic dusts, pesticides, herbicides and diesel exhaust fumes [2, 4-8]. Using lifetime job history minimises the chance of HWSE bias that might have been present in our earlier cross-sectional study. This bias could explain the attenuation of the exposure-response trend for agriculture-related jobs at the highest exposure levels ( $>10$ years) found in the current analysis [19]. Of note, within the agriculture sector, "gardeners/groundsmen" emerged at increased COPD risk; this has not been observed before, but the finding is plausible given the potential exposure to hazardous airborne 
TABLE 3 Prevalence ratios (PRs) and 95\% confidence intervals of chronic obstructive pulmonary disease (COPD) risk spirometry-defined as forced expiratory volume in $1 \mathrm{~s}$ (FEV1)/ forced vital capacity (FVC) below lower limit of normal for categories of lifetime job duration (years) in "sport-related occupations" before and after restriction for "super-normal" lung bias in the UK Biobank study

Healthy exposed Cases exposed PR $(95 \% \mathrm{CI}) \quad \mathrm{p}$-value for trend

\begin{tabular}{lcccc}
\hline $\begin{array}{l}\text { 3442-sports coach, athlete, } \\
\quad \text { instructor, scorer }\end{array}$ & & & & \\
$\quad 0.5-10$ years & 122 & 19 & $1.78(1.15-2.76)$ & 0.004 \\
$\quad>10$ years & 80 & 12 & $1.69(0.92-3.09)$ & \\
After restriction for both & & & & \\
$\quad$ FEV and FVC $>\mathbf{1 0 0 \%}$ predicted & 77 & 8 & $1.43(0.55-2.73)$ & 0.288 \\
$\quad \begin{array}{l}0.5-10 \text { years } \\
>10 \text { years }\end{array}$ & 47 & 4 & $1.28(0.51-3.20)$ &
\end{tabular}

Data are presented as $\mathrm{n}$, unless otherwise stated. PRs $(95 \% \mathrm{Cl})$ calculated using a Poisson model with robust variance adjusted for sex, study centre (22 categories), age (5-year categories) and lifetime smoking exposure (ever, pack-years and years since quitting). Reference category: "always office workers"; healthy: non-COPD cases; cases: COPD cases.

substances such as organic dusts, pesticides, bacteria and fungi spores potentially present in compost materials. Other new interesting jobs emerged in the manufacturing sector: "plastic processors", "paper/ wood operatives" (among never-smokers only), "sculptors/painters" and "warehouse stackers", which deserve further attention due to potential exposure at work to a wide range of hazards including fumes (e. g. heating of plastics, diesel fumes), dusts (e.g. wood, paper, metals, paint pigments) and vapours (e.g. paint solvents, glues). Of note, for warehouse stackers who use diesel powered vehicles the exposure may occur in confined spaces or where ventilation is insufficient.

Interestingly, we found a super-normal lung bias effect that led to an observed increased risk of COPD among sport occupations. This has been reported previously in the occupational health setting [18]. From a qualitative review of the collected job-title descriptions within this cohort, approximately one-third were ex- or current professional swimmers, so potentially exposed to chloramines, which are known respiratory irritants and sensitisers $[20,21]$. It is still debated whether this phenomenon is due to exercise-induced accelerated alveoli growth in those who start intense physical activity such as swimming in childhood, or merely the selection of children with genetically larger lungs into these highly physically demanding sports $[22,23]$. Nevertheless, we would suggest that epidemiological studies should rule out this potential selection bias when evaluating spirometry-defined COPD risk among this category of workers.

Our study has several strengths. First, its large sample size, which, to the best of our knowledge, is greater than that of any previous study conducted on lifetime occupations and COPD risk (spirometry-defined) in a general population. The large sample let us confirm our findings among never-smokers and never-asthmatics, thus ruling out any potential residual confounding effect of tobacco smoking and disease misclassification with asthma, respectively. Of note, the important impact on our risk estimates of restricting the analyses to never-smokers confirms the strong causal relationship between COPD and smoking, and suggests that large studies among never-smokers should be performed when assessing the effect of occupational risk factors. Second, our study is not limited to an industrial sector, but covers a broad variety of occupations and industry sectors in the general working population, increasing the chance of our analysis to detect all the potential COPD-high-risk jobs. Third, the high quality of the spirometry definition of the COPD outcome, based on acceptable and repeatable manoeuvres according to almost all ATS/ERS criteria [12]. Fourth, the reliable occupational exposure assessment, based on a new validated automatic online tool, OSCAR, which coded each job collected using standard occupational codes blind to COPD status, ruled out any differential misclassification. Finally, the collection of individual lifetime job-histories that allowed us to increase statistical power, to minimise the risk of a HWSE bias and to explore exposure-response trends by using categories of job duration, so supporting the validity of our positive risk associations.

Nevertheless, we acknowledge some limitations: although all of the 353 four-digit SOC 2000 codes were present in the UK Biobank population, there were only small numbers in some job categories (e.g. coal miners); this may have occurred because they were not prevalent in the populations recruited or because 
people in these job categories were less likely to respond to UK Biobank study overall and/or less likely to respond to the OSCAR tool. Additionally, for some jobs, the low number of subjects in the highest lifetime job duration categories may have prevented us detecting statistically significant exposure-response trends. This is expected in a low-exposed general population sample [24], and even more in a voluntary cohort that was designed to be internally valid, but not representative of the entire UK population [25]. Therefore, we cannot rule out a certain degree of selection bias due to the nature of the entire Biobank cohort (i.e. more females, educated, non-smokers and mostly White) that might have affected our ability to detect increased COPD risk in some of the few expected at-risk occupations. Spirometry tests were conducted without bronchodilation, but we managed to overcome a potential COPD misclassification with asthma by restricting our analyses to those reporting never having had a diagnosis of, or treatment for, asthma. Of note, the COPD prevalence estimated in our sample was within the range of that expected in the UK based on our spirometry definition, and study population age range [13]. Finally, even if we used a standard job coding classification and a reliable occupational assessment tool, we cannot rule out a certain degree of job misclassification, but this is likely to be non-differential, thus resulting in a "bias towards the null" that would underestimate the true associations [26].

In conclusion, analysing the lifetime job-histories of $\sim 100000$ individuals from a general population, we found that six specific occupations are associated with an increased COPD risk. Given the unprecedented large sample, and the consistency of our results in sensitivity analyses, in particular in never-smokers, we are confident of the validity of these findings and that they deserve further investigation. Occupational risk factors for COPD are both important and preventable: the identification of the jobs at high-risk is pivotal to inform focussed workplace preventive strategies. This should be a public health policy priority, in particular in ageing working populations where the associated costs in terms of morbidity and disability are, regrettably, expected to increase.

Acknowledgements: We would like to thank Naomi Allen, Heather Young and Alan Young (Clinical Trial Service Unit and Epidemiological Studies Unit, Nuffield Dept of Population Health, University of Oxford, Oxford, UK), for their essential contribution in implementing the OSCAR tool in the UK Biobank web platform.

Author contributions: S. De Matteis conceived and conducted the statistical analyses, interpreted the results, and wrote the article. P. Cullinan, L. Rushton and D. Jarvis, as PIs of the project, coordinated and supervised the analyses, and contributed to the interpretation of the results. All the authors contributed to the project and reviewed the final version of the manuscript.

Conflict of interest: None declared.

Support statement: This work was supported by contract OH1511 from the Health and Safety Executive (HSE). This research has been conducted using the UK Biobank Resource under Application Number 178. This publication and the work it describes, including any opinions and/or conclusions expressed, are those of the authors and do not necessarily reflect HSE policy. Funding information for this article has been deposited with the Crossref Funder Registry.

\section{References}

1 GBD 2016 Disease and Injury Incidence and Prevalence Collaborators. Global, regional, and national incidence, prevalence, and years lived with disability for 328 diseases and injuries for 195 countries, 1990-2016: a systematic analysis for the Global Burden of Disease Study 2016. Lancet 2017; 390: 1211-1259.

2 Blanc PD. Occupation and COPD: a brief review. J Asthma 2012; 49: 2-4.

3 Hnizdo E, Sullivan PA, Bang KM, et al. Association between chronic obstructive pulmonary disease and employment by industry and occupation in the US population: a study of data from the Third National Health and Nutrition Examination Survey. Am J Epidemiol 2002; 156: 738-746.

4 Omland O, Würtz ET, Aasen TB, et al. Occupational chronic obstructive pulmonary disease: a systematic literature review. Scand J Work Environ Health 2014; 40: 19-35.

5 Doney B, Hnizdo E, Graziani M, et al. Occupational risk factors for COPD phenotypes in the Multi-Ethnic Study of Atherosclerosis (MESA) Lung Study. COPD 2014; 11: 368-380.

6 Lytras T, Kogevinas M, Kromhout H, et al. Occupational exposures and 20-year incidence of COPD: the European Community Respiratory Health Survey. Thorax 2018; 73: 1008-1015.

7 Würtz ET, Schlünssen V, Malling TH, et al. Occupational COPD among Danish never-smokers: a population-based study. Occup Environ Med 2015; 72: 456-459.

8 Kraï-Leleu M, Lesage FX, Drame M, et al. Occupational risk factors for COPD: a case-control study. PLoS One 2016; 11: e0158719.

9 Sudlow C, Gallacher J, Allen N, et al. UK Biobank: an open access resource for identifying the causes of a wide range of complex diseases of middle and old age. PLoS Med 2015; 12: e1001779.

10 De Matteis S, Jarvis D, Hutchings S, et al. Occupations associated with COPD risk in the large population-based UK Biobank cohort study. Occup Environ Med 2016; 73: 378-384.

11 De Matteis S, Jarvis D, Young H, et al. Occupational self-coding and automatic recording (OSCAR): a novel web-based tool to collect and code lifetime job histories in large population-based studies. Scand J Work Environ Health 2017; 43: 181-186.

12 Miller MR, Hankinson J, Brusasco V, et al. Standardisation of spirometry. Eur Respir J 2005; 26: 319-338.

13 Swanney MP, Ruppel G, Enright PL, et al. Using the lower limit of normal for the FEV1/FVC ratio reduces the misclassification of airway obstruction. Thorax 2008; 63: 1046-1051. 
14 Hankinson JL, Odencrantz JR, Fedan KB. Spirometric reference values from a sample of the general U.S. population. Am J Respir Crit Care Med 1999; 159: 179-187.

15 Smith LJ. The lower limit of normal versus a fixed ratio to assess airflow limitation: will the debate ever end? Eur Respir J 2018; 51: 1800403.

16 Office for National Statistics. Standard Occupational Classification 2000. Date last accessed: October 2018. https:// www.ons.gov.uk/methodology/classificationsandstandards/standardoccupationalclassificationsoc/socarchive.

17 Zou G. A modified Poisson regression approach to prospective studies with binary data. Am J Epidemiol 2004; 159: $702-706$.

18 Townsend MC, Occupational, Environmental Lung Disorders Committee. Spirometry in the occupational health setting - 2011 update. J Occup Environ Med 2011; 53: 569-584.

19 Stayner L, Steenland K, Dosemeci M, et al. Attenuation of exposure-response curves in occupational cohort studies at high exposure levels. Scand J Work Environ Health 2003; 29: 317-324.

20 Rosenman KD, Millerick-May M, Reilly MJ, et al. Swimming facilities and work-related asthma. J Asthma 2015; 52: $52-58$.

21 Thickett KM, McCoach JS, Gerber JM, et al. Occupational asthma caused by chloramines in indoor swimming-pool air. Eur Respir J 2002; 19: 827-832.

22 Armour J, Donnelly PM, Bye PT. The large lungs of elite swimmers: an increased alveolar number? Eur Respir J 1993; 6: 237-247.

23 Hsia CC. Signals and mechanisms of compensatory lung growth. J Appl Physiol 2004; 97: 1992-1998.

24 Pearce N, Checkoway H, Kriebel D. Bias in occupational epidemiology studies. Occup Environ Med 2007; 64: $562-568$.

25 Rothman KJ, Gallacher JE, Hatch EE. Why representativeness should be avoided. Int J Epidemiol 2013; 42: $1012-1014$

26 McGuire V, Nelson LM, Koepsell TD, et al. Assessment of occupational exposures in community-based case-control studies. Annu Rev Public Health 1998; 19: 35-53. 